\title{
NÍVEL DE SUSTENTABILIDADE AMBIENTAL DA COMUNIDADE RURAL FAZENDA DO POVO DE IPIAÚ, BAHIA, BRASIL
}

\author{
Nelma Lima Bruno ${ }^{1}$ \\ Paulo César Bahia de Aguiar ${ }^{2}$ \\ Christiana Cabicieri Profice ${ }^{3}$ \\ Marcelo Inácio Ferreira Ferraz ${ }^{4}$ \\ José Levi Furtado Sampaio ${ }^{5}$
}

Resumo: Este artigo tem como principal objetivo apresentar a avaliação do nível de sustentabilidade ambiental atual da Comunidade Rural Fazenda do Povo de Ipiaú, Bahia. Como metodologia, construiu-se um formulário semiestruturado (abordagem bottom-up) o qual foi aplicado a 111 representantes de famílias; e um segundo, aos representantes das famílias que dispunham de unidades produtivas. Levantaram-se dados secundários por meio de pesquisa bibliográfica e documental. No tratamento dos dados, para avaliação do nível de sustentabilidade ambiental da comunidade, por meio de indicadores, utilizou-se uma escala adaptada de Likert. Como resultado, obteve-se que a Comunidade alcançou o índice geral de sustentabilidade ambiental de 1,794 - nível geral de média sustentabilidade ambiental. As três dimensões avaliadas se encontram no nível de média sustentabilidade ambiental, não alcançando o limiar de sustentabilidade "3,2" - limite mínimo da alta sustentabilidade.

Palavras-chave: Desenvolvimento sustentável; Comunidades rurais; Sustentabilidade ambiental; Indicadores de sustentabilidade

\section{ENVIRONMENTAL SUSTAINABILITY IN PEOPLE FARM RURAL COMMUNITY, IPIAÚ, BAHIA, BRAZIL}

\begin{abstract}
This paper present and discuss the current level of environmental sustainability of People Farm Rural Community, Ipiaú, Bahia, Brazil. Then we present a description of the research design, including the procedures adopted for the construction and application of the primary data collection instrument in a bottom-up approach. We did the application of a semi structured questionnaire to 111 families, and a second semi structured form applied to the families that have production units. We also capture GPS points at different times. The collection of secondary data was through bibliographical and documentary research. Obtained that the community reached the general index of environmental sustainability 1,794, which puts the overall level of average environmental sustainability. The three dimensions evaluated
\end{abstract}

\footnotetext{
${ }^{1}$ Graduada em Geografia pela Universidade do Estado da Bahia - UNEB Campus VI de Caetité. Especialista em Agroecologia Aplicada a Agricultura Familiar - Residência Agrária, e Mestra em Desenvolvimento Regional e Meio Ambiente pela Universidade Estadual de Santa Cruz - UESC, em Ilhéus, Bahia, Brasil. E-mail: nelmalima06@hotmail.com

${ }^{2}$ Graduado em Geografia, Especialista em Agroecologia Aplicada a Agricultura Familiar - Residência Agrária, e Mestre em Desenvolvimento Regional e Meio Ambiente pela Universidade Estadual de Santa Cruz - UESC, em Ilhéus, Bahia, Brasil. E-mail: prof.pauloaguiar@bol.com.br

${ }^{3}$ Doutora em Psicologia Social pela Universidade Federal do Rio Grande do Norte, Brasil. Professora Adjunta do Departamento de Filosofia e Ciências Humanas da UESC.E-mail: ccprofice@uesc.br

${ }^{4}$ Doutor em Estatística e Experimentação Agropecuária pela Universidade Federal de Lavras - UFLA. Professor Titular do Departamento de Ciências Econômicas e Tecnológicas da Universidade Estadual de Santa Cruz. Email:mfferraz@uesc.br

${ }^{5}$ Doutor em Geografia pela Universidade de São Paulo - USP. Professor da Universidade Federal do Ceará. Email: leviufc@gmail.com
} 
are in the average environmental sustainability level, not reaching the sustainability threshold "3.2" - minimum high sustainability.

Keywords: Sustainable development; Environmental sustainability; Rural communities; Indicators

\section{NÍVEL DE SOSTENIBILIDAD AMBIENTAL DE LA COMUNIDAD RURAL GRANJA DE PUEBLO EN IPIAÚ, BAHÍA, BRASIL}

Resumen: Este artículo tiene como objetivo evaluar la sostenibilidad ambiental de la Comunidad Rural Granja de Pueblo en Ipiaú, Bahía. Para evaluar la sostenibilidad ambiental de la comunidad se preparó una investigación semi-estructurada, basada en un enfoque de bottom-up. A través de un enfoque multimétodo, que se hizo la consulta de los documentos locales y los datos secundarios; para recoger los datos de campo se utilizaron cuestionario semi-estructurado, entrevistas, observación directa, registros fotográficos e informes. Como resultado se obtuvo que la comunidad se encuentra a una media de sostenibilidad ambiental, la misma condición de sus dimensiones.

Palabras clave: Desenvolvimento sostenibilidad; Comunidades rurales; Sostenibilidad ambiental; Indicadores de sustentabilidade

\section{Introdução}

Diferentes estudos, tanto em âmbito nacional quanto internacional, vêm apontando o grande potencial que comunidades humanas localizadas possuem para a promoção da equidade social, acesso a bens e serviços primordiais ao desenvolvimento, e para a satisfação das aspirações humanas em equilíbrio com a conservação ambiental. Portanto, estudar essas comunidades em suas especificidades, sobretudo no que se refere a sua sustentabilidade ambiental, é importante para a compreensão da realidade em que as mesmas se encontram; para fornecer subsídios voltados à adoção de políticas eficazes de desenvolvimento desses espaços buscando a melhoria de suas condições; e para a busca da construção de comunidades sustentáveis e saudáveis.

Nessa direção, o estudo que empreendemos procurou avaliar a sustentabilidade ambiental de uma comunidade rural (a Comunidade Rural Fazenda do Povo - CRFP, do município de Ipiaú, Microrregião Ilhéus-Itabuna, Bahia) dentro de uma perspectiva atual de estudo de comunidades humanas localizadas. A pesquisa efetivada esteve relacionada ao interesse em compreender os diferentes tipos de relações que se estabelecem entre os atores sociais (tanto os de dentro da comunidade quanto os de fora que agem sobre ela), as especificidades de suas ações, escolhas, interesses e relações com o ambiente - o que efetivamente contribui para o seu estado atual. Adotou-se nessa perspectiva a ideia da 
sustentabilidade tridimensional de Mauerhofer (2008), ou seja, 3D. As categorias de análise adotadas foram os três escopos medidos: social, econômico e do uso e gestão dos recursos naturais e tecnológicos, ou seja, as três dimensões de sustentabilidade consideradas.

Um modelo internacionalmente aceito e que tem se adequado satisfatoriamente ao estudo de realidades locais (e que foi por nós utilizado) tem sido a identificação e seleção de indicadores de sustentabilidade enquanto instrumento de dimensionamento e monitoramento das características de determinado sistema, envolvendo os moradores locais e partes interessadas.

Os indicadores de sustentabilidade exigem uma visão de mundo sistemática, relacionando a economia, o ambiente e a sociedade de uma dada comunidade, sendo importantes instrumentos para o planejamento e tomadas de decisões, permitindo criar cenários e acompanhar os resultados de decisões tomadas pelos envolvidos (BELLEN, 2006). Essa proposta é primordial para o entendimento desses ambientes e para a busca da construção de comunidades sustentáveis.

Levando em consideração que diferentes fatores endógenos e exógenos interferem nas dimensões de sustentabilidade de comunidades rurais, causando-lhes impactos em níveis diferenciados conforme a dimensão, as necessidades dos moradores ou dos agentes externos, e o grau dessas ações, a pesquisa desenvolvida partiu da seguinte pergunta de investigação: em qual nível de sustentabilidade ambiental se encontra a Comunidade Rural Fazenda do Povo, de Ipiaú, Bahia? Portanto, este artigo tem como principal objetivo avaliar o nível de sustentabilidade em que se encontra a referida comunidade rural.

A hipótese adotada partiu da proposição de que a referida comunidade se encontra em um nível global de baixa sustentabilidade ambiental das dimensões consideradas, acompanhando a tendência de demais assentamentos brasileiros.

A metodologia aplicada para a efetivação da pesquisa envolveu vários procedimentos realizados nas etapas de campo e nas etapas de laboratório. O ponto de partida para a realização da pesquisa foi o contato prévio com representantes do Poder Público Municipal e contato prévio com lideranças da comunidade, intermediado por representes do Poder Público Municipal (no primeiro semestre de 2014), os quais autorizaram a pesquisa na comunidade. A pesquisa no local, no entanto, só se iniciou depois da aprovação do Comitê de Ética em Pesquisas com Seres Humanos (CEP) da Universidade Estadual de Santa Cruz, por meio do parecer $n^{\circ} 832.751$. 
Para fundamentar a pesquisa, reforçar as discussões e se ter uma visão mais clara do objeto pesquisado, fez-se levantamento e estudo de materiais bibliográficos e documentais (livros impressos e publicados na internet, artigos publicados na internet, e documentos obtidos junto ao Poder Público Municipal e à associação da comunidade: escritura da terra da Fazenda do Povo; contrato de comodato das famílias assentadas, que torna legitimo o uso da terra; e o Estatuto da Associação da comunidade).

As etapas de campo envolveram a efetivação das seguintes atividades: a) reunião participante, na sede da associação da comunidade, para apresentação do projeto de pesquisa e identificação e seleção de indicadores prioritários da comunidade - utilizou da abordagem Bottom-up (de baixo para cima), a qual reflete valores e prioridades. b) elaboração de mapa mental junto com um morador e uma liderança da comunidade, e neste identificou-se diferentes formas de ocupação da terra: plantios, capoeiras, matas, brejos e construções; e levantamento, mediante o uso do Sistema de Posicionamento Global (GPS), de coordenadas geográficas de pontos estratégicos identificados anteriormente no mapa mental para georreferenciamento da área e sua posterior visualização na imagem de satélite obtida do Google Earth. c) pré-teste do instrumento de coleta de dados primários (formulário semiestruturado) na própria comunidade envolvendo doze residências. d) aplicação do instrumento de coleta de dados primários (formulário semiestruturado) por meio de um censo da comunidade, num total de 111 famílias pesquisadas (correspondente a 111 residências) perfazendo um total de 416 pessoas identificadas na comunidade - aplicou-se o formulário em cada domicilio a apenas um representante de família (homem ou mulher), e não se levou em consideração o fato de em uma mesma residência haver mais de uma família (onde aconteceu); fizeram-se ainda registros de depoimentos da população. e) observação direta com a finalidade de levantamento e registro da infraestrutura da comunidade, e registros fotográficos. f) observação direta das unidades de produção (UP) das famílias assentadas, perfazendo um total de 77 unidades, e aplicação de um segundo formulário semiestruturado com questões voltadas para identificar as condições de manejo das áreas das UP, práticas conservacionistas dos recursos naturais (solo, água e vegetação), recursos tecnológicos utilizados, bem como identificar os tipos de cultivos desenvolvidos e sua finalidade (consumo familiar, comercialização e subsistência), e a situação de aquisição dos lotes (UP). Fez-se ainda levantamento de coordenadas geográficas dessas unidades por meio de GPS. 
No que se refere às etapas de laboratório, as mesmas envolveram as seguintes atividades: levantamento de dados secundários junto ao Instituto Brasileiro de Geografia e Estatística - IBGE; codificação e geração de planilha para tratamento de dados primários e de dados secundários no programa Excel; processamento e análise dos dados pelo Statistical Package for the Social Science (SPSS), versão 20; e elaboração de mapas da comunidade no ArcGis 10.2.2.

Como modelo teórico, utilizou-se um estudo exploratório de dados, baseando-se em alguns tópicos da Estatística Descritiva, tais como: representação tabular, tabelas cruzadas e representação gráfica, frequências, e correlações entre variáveis (correlação não paramétrica de Spearman's, para correlação entre variáveis nominais e ordinais).

Os indicadores de sustentabilidade foram definidos com base na abordagem Bottom-up, e na literatura que fundamenta a proposta de pesquisa. Esses indicadores foram avaliados para se obter o nível de sustentabilidade ambiental da CRFP. Cada indicador foi identificado a partir de um tema correspondente em uma das três dimensões de sustentabilidade adotada pela pesquisa: social, econômica, e uso e gestão dos recursos naturais e tecnológicos. Foram considerados sete temas na dimensão social, sete temas na dimensão econômica e quatro temas na dimensão uso e gestão dos recursos naturais e tecnológicos.

Para dimensionar cada indicador criou-se uma escala, adaptada de Likert, variando entre 0 e 4 , de forma que o valor 0 representa a condição negativa e 4 representa a condição positiva do indicador. Alguns indicadores foram analisados de forma singular; outros, de forma agregada - critério este que variou conforme o indicador selecionado. Em cada dimensão obteve-se um subíndice, que por sua vez possibilitaram a geração de um índice geral. A soma do resultado de cada indicador dentro de um tema em uma dimensão dividido pelo número de indicadores contidos naquele tema deu o resultado do tema. Por sua vez, a soma do resultado de cada tema da dimensão dividido pela quantidade de temas contidos na dimensão deu como resultado o subíndice de sustentabilidade obtido pela dimensão (o mesmo procedimento vale para cada dimensão). A soma do subíndice de cada dimensão dividido pelo número de dimensões dá como resultado o índice geral ou nível geral de sustentabilidade ambiental da comunidade. De forma geral, a obtenção do índice geral de sustentabilidade ambiental da comunidade pode ser representada da seguinte forma: indice geral de sustentabilidade ambiental da comunidade $=\sum \mathrm{Y}_{\mathrm{j}} / \mathrm{n}$, onde $\mathrm{Y}_{j}$ corresponde ao valor do nível 
(subíndice) de sustentabilidade ambiental da comunidade na dimensão ${ }_{j}$, podendo variar de 0 a 4, e $n$ o número de dimensões consideradas, ou seja, três dimensões.

Com a finalidade de avaliar a sustentabilidade ambiental da comunidade em cada dimensão considerada a partir dos subíndices obtidos, e a sustentabilidade ambiental geral da comunidade a partir do índice geral, criaram-se, por meio de formulação própria, cinco níveis de sustentabilidade, a saber: de 0 a $<0,8=$ nível de baixa sustentabilidade ambiental; de 0,8 a $<1,6$ = nível de baixa-média sustentabilidade ambiental; de 1,6 a $<2,4=$ nível de média sustentabilidade ambiental; de 2,4 a $<3,2$ = nível de média-alta sustentabilidade ambiental; de 3,2 $\mathrm{a} \leq 4=$ nível de alta sustentabilidade ambiental. Nesse método adotado, a sustentabilidade ambiental da comunidade pode estar em qualquer um dos cinco níveis, onde o menor nível (0 $\mathrm{a}<0,8)$ representa situação crítica da comunidade, ou seja, sustentabilidade não alcançada, e o maior nível $(3,2 \mathrm{a} \leq 4)$ representa elevada sustentabilidade da comunidade.

\section{Comunidade rural: conceito, sustentabilidade ambiental e desafios}

Diferentes foram os conceitos construídos e propostos no transcorrer do tempo para o termo "comunidade" em distintas linhas de pensamento e interesses ideológicos variados.

Considerando-se as diferentes concepções de comunidade existentes na literatura, neste estudo adotou-se como conceito essencial de comunidade a definição de Castilho; Arenhardt e Le Bourlegat (2009), complementado pelas contribuições de Collins (2010) e de Nguiraze e Aires (2011), onde por comunidade entendem-se certos agrupamentos de pessoas que satisfazem alguns critérios, como o manter relação de interação, compreensão, partilha e solidariedade/ colaboração para um fim comum (coesão social), sendo a cultura, as tradições da coletividade, o sentimento de pertencimento, a territorialidade, a permanência no local, seus valores e a participação ativa dos indivíduos, fatores fundamentais que a constitui enquanto tal (CASTILHO; ARENHARDT; LE BOURLEGAT, 2009); se constituem em espaços de engajamento político e de contestação (COLLINS, 2010); e se configura em uma unidade política, onde os mediadores locais (governamentais ou não governamentais) são importantes agentes externos com capacidade de proporcionar bens públicos e outros serviços de interesse coletivo (NGUIRAZE; AIRES, 2011). Por sua vez, o que vem a ser comunidade rural também é apresentado de formas diferenciadas nas literaturas, indo desde as visões mais simplistas para o contexto atual e isolacionistas ao ambiente natural, práticas agrárias e relações de parentesco ou de proximidade homogeneizante, até aquelas visões que entendem 
as comunidades rurais como em estreita relação com o mundo urbano, com o desenvolvimento de atividades que complementam ambos os espaços (rural e urbano). Sendo assim, o conceito de comunidade aqui adotado se estende para o entendimento de comunidades rurais, respeitando as especificidades do contexto destas.

Portanto, entendemos que essa noção de comunidade é a que mais se aproxima da ideia de sustentabilidade ambiental que utilizamos para nortear nosso estudo (a sustentabilidade 3D). Desse modo, a noção de comunidades sustentáveis nos parece mais apropriado do que a de desenvolvimento sustentável, pois privilegia a necessidade do resgate do conceito de sustentabilidade ligado ao de bem-estar e qualidade de vida das comunidades e sociedades humanas, reafirmando seus elementos culturais e históricos, desenvolvendo novas solidariedades, o respeito à natureza (e não a mercantilização da biodiversidade), propiciando a manutenção da relação harmoniosa entre sociedade e natureza (DIEGUES, 2003). Sendo assim, essas comunidades, em razão dos seus amplos conhecimentos sobre o ambiente, suas técnicas e seus costumes, podem ser trabalhadas enquanto mecanismo para se alcançar o equilíbrio entre diferentes dimensões de sustentabilidade, e, por consequência, para a promoção da sustentabilidade ambiental.

Por ambiente de uma comunidade entende-se não apenas o entorno geográfico, mas também os próprios agrupamentos humanos, as relações que se estabelecem, as instituições, a economia, etc; e, por ambiental, entende-se a categorização dos componentes e características funcionais que compõem o ambiente de uma comunidade, os quais dão suporte para que ela exista (social, econômico, ecológico, político, etc). Sendo assim, a sustentabilidade ambiental está ligada a sustentação, de forma equilibrada, desses sistemas. Segundo Leff (2001, p. 324), a "qualidade de vida depende da qualidade do ambiente para [se] chegar a um desenvolvimento equilibrado e sustentável..."; dessa forma, Alencar-Linard, Saeed-Khan e Lima (2015) entendem que a sustentabilidade ambiental resulta da influência mútua das condições ecológicas, biológicas, socioculturais e econômicas.

O ambiente de uma comunidade [rural] é resultante de um conjunto de ações coletivas que culminam na construção de territórios de vida e trabalho, sendo, portanto, nesse contexto que os laços de pertencimento a uma comunidade são criados, os quais resultam em relações de proximidade, como de vizinhança e compadrio - característicos de uma comunidade (BRANDEMBURG, 2010). 
A sustentabilidade desses ambientes deve ser vista, estudada e proposta como uma busca permanente de novos pontos de equilíbrio entre diferentes dimensões, como a social, econômica e ecológica, em que é necessário adotar estilos de desenvolvimento rural e de agricultura que assegurem maior sustentabilidade dos recursos naturais e equidade social (CAPORAL; COSTABEBER, 2002).

Segundo Marques (2002, p. 100), “as definições elaboradas sobre o campo e a cidade podem ser relacionadas a duas grandes abordagens: a dicotômica e a de continuum". Enquanto no primeiro caso "o campo é pensado como meio social distinto que se opõe à cidade"; no segundo, "defende-se que o avanço do processo de urbanização é responsável por mudanças significativas na sociedade em geral, atingindo também o espaço rural e aproximando-o da realidade urbana" (Ibid.). Aguiar et al. (2015, p. 89) pontuam que, no contexto atual, o rural e o urbano são espaços que "fazem parte de um mesmo processo, são articulados, exercem atração e possuem funções que se complementam - embora possuam particularidades específicas, as quais tornam cada um desses espaços objetos singulares a serem elucidados". Portanto, as comunidades rurais, conquanto habitem esses espaços rurais e vivam suas experiências cotidianas primordialmente nesses ambientes, estão inseridas em um processo maior de relação de complementaridade entre ambos os espaços (rural-urbano).

No Brasil, um problema que vem afetando o campo nas últimas décadas é o processo esvaziamento, principalmente por parte de jovens em busca de melhores oportunidades de trabalho, com predomínio da saída das mulheres rumo aos centros urbanos, se constituindo em duas faces de uma realidade que vem levando ao envelhecimento da população e a masculinização do meio rural (CAMARANO e ABRAMOVAY, 1998). Outros problemas que afetam muitos espaços rurais se referem aos baixos níveis de organização, coesão social e produtiva, de assistência técnica e de extensão rural, fatos que muitas vezes decorrem, dentre outros motivos, em consequência das relações de poder dentro das comunidades, ou mesmo pela omissão dos órgãos e instituições gestores (PEREIRA; SILVA e SILVA FILHO, 2014).

\section{As limitações do Conceito de Desenvolvimento Sustentável e a Sustentabilidade Ambiental}

Por desenvolvimento sustentável, segundo o relatório Bruntland de 1987, entende-se o desenvolvimento que satisfaz as necessidades do presente sem comprometer a capacidade de as futuras gerações satisfazerem as suas próprias necessidades (BRÜSEKE, 2001). Por sua 
vez, por sustentabilidade ambiental entende-se não apenas a sustentação dos elementos ambientais, mas, sobretudo, o equilíbrio entre três dimensões de sustentabilidade: econômica, social e dos recursos naturais - o tripé 3D, onde o capital natural se constitui no limite da sustentabilidade (MAUERHOFER, 2008).

Conquanto o conceito de desenvolvimento sustentável apresente alguns aspectos que se relacionam com o de sustentabilidade ambiental, no entanto, em sua essência ambos os conceitos são distintos e evocam objetivos diferenciados. Também o mencionado conceito de desenvolvimento sustentável apresenta significativas limitações. Acreditamos que a primeira limitação do desenvolvimento sustentável é ser uma ideia abstrata que não parte de nenhum contexto específico e, portanto, também não se encaixa em todo e qualquer contexto. Seu segundo problema seria uma explícita posição ambígua, ao mesmo tempo em que devemos efetuar uma visão do todo podemos adotar apenas uma perspectiva, a econômica, que é afinal quem determina o próprio desenvolvimento, em qualquer escala.

Sendo assim, a primeira limitação do conceito de desenvolvimento sustentável reside em sua absoluta generalidade, o fato dele ser uma ideia genérica que não parte da apreciação de nenhum contexto específico e que pretende ser uma regra universal ou, melhor ainda, global. De fato, ele implica na globalização da preponderância da dimensão econômica da sustentabilidade sobre as demais, justificando a usurpação de recursos naturais e sociais por setores econômicos dominantes. Neste sentido, o desenvolvimento sustentável ao contrário de propor uma mudança para a distribuição equânime do bem estar social, acaba por referendar a desigualdade por meio da manutenção da concentração de poder e de renda. Na verdade o desenvolvimento assim entendido é de fato o mesmo que crescimento, da concentração de renda e da desigualdade social bem como de degradação da natureza e das comunidades locais que dela dependem diretamente. No Brasil não nos faltam exemplos de empreendimentos do desenvolvimento sustentável que tiveram e ainda têm consequências desastrosas para as dimensões sociais e naturais locais como a construção de Belo Monte e a expansão do agronegócio, subsidiados pelo poder público em escusas parcerias com o poderio econômico privado. Sabemos como o desenvolvimento sustentável pode ser fachada para a manutenção da desigualdade social no acesso a terra, ao lucro dela retirado e a serviços públicos de educação, saúde e bem estar.

Contudo, o desenvolvimento sustentável não pode ainda simplesmente ser jogado fora. Como conceito ele já foi e é ainda muito difundido e pensado em diferentes contextos. Assim, 
ao se incorporar na realidade ele já supera a sua primeira limitação que é justamente o fato de ter sido formulado como uma ideia "global", uma regra a ser aplicada em qualquer escala ou contexto. Quando se invoca a ideia do desenvolvimento sustentável se traz junto a compreensão, ainda que muito vaga e limitada, do que é sustentabilidade, e assim podemos dizer que é meio caminho andado na direção de um entendimento mais complexo do assunto. O que fica faltando é a compreensão realista que qualquer desenvolvimento encontra limites que podem ser incorporados ou superados, mas jamais ignorados. Além disso, o conceito predominante de desenvolvimento sustentável não deixa evidente quais são as necessidades das presentes gerações, as quais variam conforme os diferentes países, regiões, culturas, classes sociais e religiões, e as necessidades das futuras gerações não poderem ser dimensionadas pelo fato destas ainda não existirem - permitindo apenas conjecturas (CARVALHO; BARCELLOS, 2009).

A adoção de um viés economicista que une e confunde crescimento com desenvolvimento é a segunda limitação do desenvolvimento sustentável a ser confrontada. Aqui uma pergunta de base pode auxiliar na desconstrução do mito econômico, quem é que ganha poder território e dinheiro e quem é que perde? Qualidade de vida e bem estar constituem um capital social distribuído de modo equânime? Quando fica esclarecida a íntima imbricação entre as dimensões econômicas e as sociais quebra-se a abstração do desenvolvimento sustentável e vem à tona a sustentabilidade ambiental com a incontornável realidade de suas dimensões. Portanto, a ambiguidade contida na utilização do conceito de desenvolvimento sustentável se deve substancialmente ao fato de ter-se pensado, quando de sua apropriação por parte de diferentes segmentos, apenas na sustentação econômica, em que passou a ser buscado de forma privilegiada o crescimento econômico em detrimento do desenvolvimento.

Pelas razões acima expostas e discutidas, ainda é cedo para declarar como falida a ideia do desenvolvimento sustentável. Ainda que tenhamos chegado à conclusão de que ela já nasceu comprometida pelas limitações que indicamos neste trabalho não podemos simplesmente apagá-la ou jogá-la fora. Talvez daqui a cinquenta anos algum pesquisador das ciências ambientais trate dela como coisa do passado, como uma ideia na qual ninguém mais acredita, por ter ela mesmo se tornado um arranjo insustentável. Mas hoje no cenário de discussão de temas ambientais e referentes ao desenvolvimento, a ideia de desenvolvimento sustentável ainda ocupa lugar de destaque. O que precisamos fazer é desconstrui-la por meio 
da análise da sustentabilidade ambiental de contextos específicos. Este foi o esforço que fizemos em relação à CRFP ao avaliarmos a sua sustentabilidade ambiental nas três dimensões consideradas e de forma geral e que pretendemos difundir com este trabalho. Ao discutirmos a sustentabilidade ambiental de uma comunidade rural como a CRFP pode-se considerar aspectos de sua dimensão social como o conhecimento local das práticas de manejo agrícola enquanto um saber-valor a ser compreendido e aperfeiçoado, ou, ao contrário, este mesmo conhecimento pode ser considerado um entrave à implementação de práticas agrícolas mais mecanizadas e produtivas. Hoje vemos em nível global o confronto entre os produtores das sementes transgênicas e os povos tradicionais com suas sementes crioulas.

Ao longo deste trabalho defendemos que adotar a sustentabilidade ambiental tridimensional, relacionando a ideia de desenvolvimento sustentável à sustentabilidade socioambiental e cultural de sociedades humanas, e não apenas a sustentação econômica, é um caminho para resolver a dificuldade (CAVALCANTE, 2004). Entende-se ser primordial nesse sentido a busca pelo resgate do conceito de sustentabilidade ligado ao bem estar e qualidade de vida de sociedades e comunidades humanas, reafirmando seus elementos históricos e culturais (DIEGUES, 2003) - algo que conduziria as comunidades e sociedades humanas para o desenvolvimento. Para tanto, adota-se uma perspectiva crítica do desenvolvimento sustentável e compreende-se que a sustentabilidade ambiental é composta por três dimensões: a natural, a social e a econômica.

\section{A Comunidade Rural Fazenda do Povo - CRFP}

Surgimento e desenvolvimento

Surgida de forma singular em contraste à política nacional adotada à época para a questão agrária no Brasil, a Comunidade Rural Fazenda do Povo (CRFP), primeira experiência oficial de reforma agrária no Estado da Bahia, criada no ano de 1963, teve sua gênese no mesmo momento em que o movimento das ligas camponesas em sua luta por reforma agrária era perseguido e desmantelado pelas forças da ordem militar que apoiavam os grandes proprietários rurais. A singularidade do surgimento dessa comunidade está no fato de o acesso a terra não ter decorrido da disputa contra os proprietários, como o foi comum na maioria dos assentamentos rurais surgidos a partir de meados da década 1980 na microrregião onde a CRFP está inserida (Microrregião Ilhéus-Itabuna). Essa comunidade foi criada por 
iniciativa do então prefeito municipal de Ipiaú, Sr. Euclides Neto, o qual viabilizou o assentamento das famílias iniciais por meio da doação de terras, visando ampará-las, pois em sua maioria eram constituídas de ex-trabalhadores da lavoura cacaueira e seus familiares, demitidos e desamparados em razão da crise ocorrida na região à época por conta de grande estiagem, e também em razão da situação precária de trabalho a que eram submetidos, chegando próximo à situação de escravização (e outras famílias posteriormente provindas de outras regiões do estado por distintos fatores) - ou seja, eram trabalhadores rurais sem trabalho e sem terra. Portanto, nasceu enquanto uma comunidade com relativa autonomia.

No princípio, o cultivo do arroz em áreas de brejo na agrovila da comunidade foi uma atividade bem presente. Posteriormente, contudo, foi sendo deixado de lado devido a alguns cursos hídricos próximo terem se secado; embora em períodos de grandes chuvas seja comum $\mathrm{o}$ alagamento das áreas produtivas em brejo. O cultivo de hortaliças (em especial o de hortaliças folhosas) passou a predominar nessas áreas - e hoje é a base de subsistência de grande parte das famílias da comunidade. $\mathrm{O}$ acesso à terra de forma legal nessa comunidade, desde sua origem até o ano de 2002, foi por meio de doação feita pelo Poder Público Municipal de Ipiaú; no entanto, a partir do ano de 2003, através da Lei 1.799, esse acesso legal passou a ser por meio de um Contrato de Comodato celebrado entre a prefeitura municipal e a família beneficiada - contrato a ser renovado a cada dois anos.

A CRFP, devido a ser a mais antiga comunidade criada oficialmente em assentamento de reforma agrária no Estado da Bahia, tem sido um exemplo de persistência e permanência no tempo, passando por todo o período do regime militar que comandou o país sendo uma experiência de tendência socialista em um regime de governo que normalmente perseguia pessoas e tendências nessa linha. Essa comunidade "presenciou" os movimentos de luta pela criação dos Projetos de Assentamentos Rurais de âmbito federal na microrregião onde está inserida (os PAs), iniciados em meados da década de 1980 com a luta dos posseiros em Canavieiras; e permanece até o momento enquanto uma comunidade de âmbito municipal, mesmo o município tido diferentes gestores de tendências distintas e, em alguns casos, com períodos de "confusões" políticas na administração municipal. O fato de se constituir em um patrimônio histórico municipal, e o forte sentimento de apego ao lugar por parte dos seus moradores (com forte gratidão e admiração ao originador da comunidade - o Sr. Euclídes Neto), além de alguns benefícios e assistências que o município concede aos moradores no lugar provavelmente sejam os principais fatores que contribuem para explicar a existência 
dessa comunidade por tanto tempo, e a permanência no lugar até o momento por parte de alguns dos primeiros moradores ainda vivos e/ou de seus descendentes.

As terras da CRFP configuram atualmente uma dimensão territorial total de 157 hectares e 25 ares, situadas no interior do Município de Ipiaú, às coordenadas geográficas de latitude $14^{\circ} 3$ '21.19''S e longitude $39^{\circ} 42^{\prime} 39.15^{\prime \prime} \mathrm{W}$, distando $11 \mathrm{~km}$ da sede municipal. A Microrregião Ilhéus-Itabuna, onde a CRFP está inserida, possui em torno de 85 projetos de assentamentos rurais (INCRA, 2011), sendo que alguns têm mais de dez anos de criados e outros possuem menos de dez anos. A Comunidade Rural Fazenda do Povo, embora seja um assentamento de reforma agrária, não se enquadra na categoria de projeto de assentamento rural (PA), portanto não está dentro do cômputo desses 85 PAs.

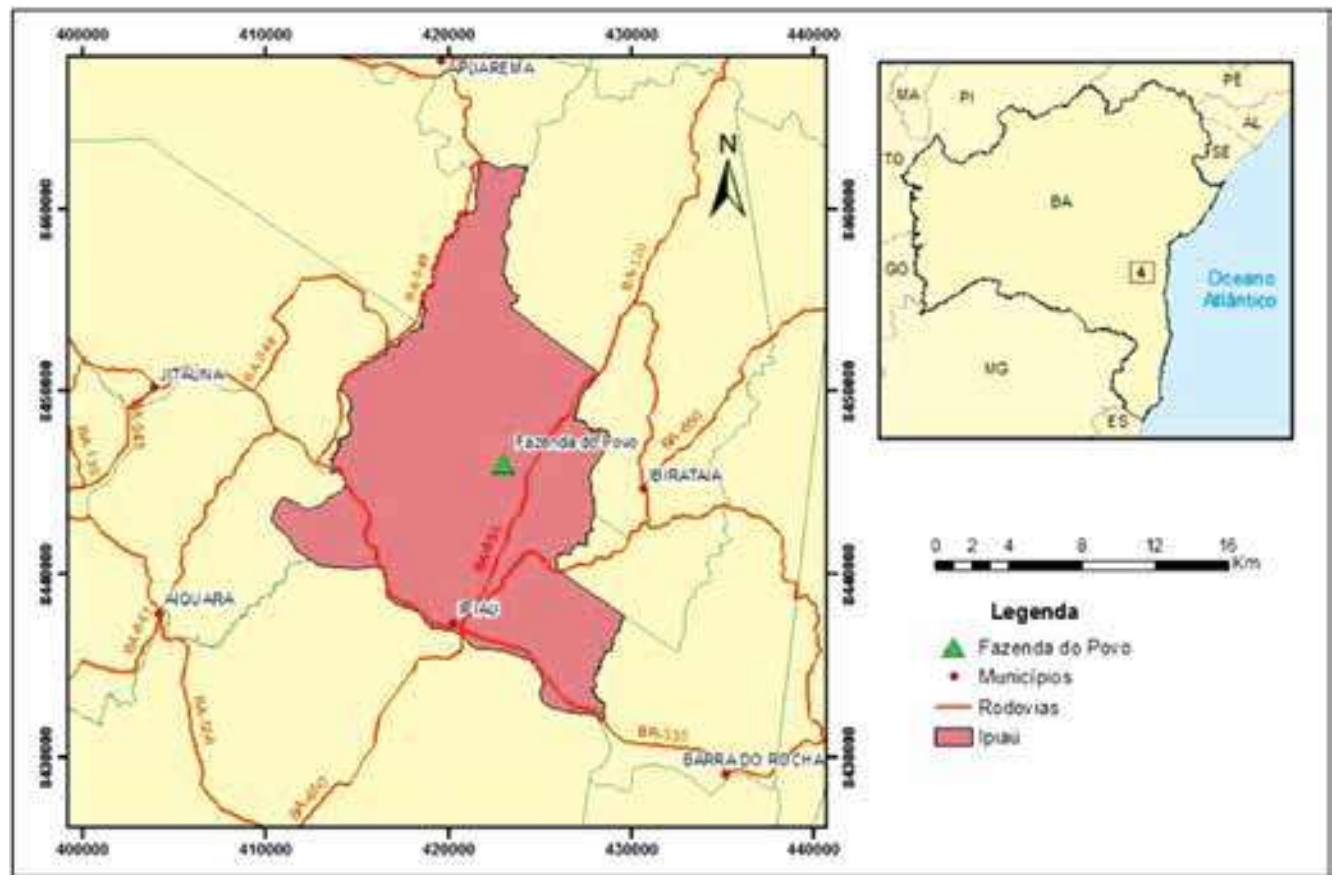

Figura 1. Localização da Comunidade Rural Fazenda do Povo no município de Ipiaú, Bahia.

Elaboração: Shigueaki, M. (2014).

Nível Geral de sustentabilidade ambiental

Avaliar o nível de sustentabilidade ambiental em que se encontra uma determinada comunidade requer que sejam levadas em consideração diferentes nuanças, indo desde os anseios e percepções dos seus moradores sobre os diferentes aspectos da dinâmica dessa comunidade em cada dimensão, até as diferentes questões não evidentemente percebidas por estes, tanto as endógenas quanto as exógenas, que influenciam diretamente o ambiente da comunidade. Sendo assim, avaliar o nível de sustentabilidade ambiental em que se encontra a 
CRFP, a partir de um sistema de indicadores, é primordial para a compreensão da sua realidade atual, permitindo identificar as dimensões e fatores mais vulneráveis - contribuindo, portanto, para a adoção de medidas por parte da própria comunidade, ou da esfera que a mantém, no sentido de buscar melhorias para os aspectos frágeis na comunidade e possibilitando o monitoramento da evolução da sustentabilidade ambiental desta no tempo.

As respostas dadas pelos moradores da comunidade entrevistados aos indicadores de sustentabilidade apresentados na forma de questões, dentro dos intervalos da escala adota que representam estágios de qualidade ambiental, apontou na direção de uma qualidade média de sustentabilidade ambiental da comunidade. O nível geral obtido para a comunidade, por meio desses indicadores, foi representado pela pontuação geral 1,794 , ou seja, dentro do intervalo 1,6 a $<2,4$ na escala de sustentabilidade adotada " 0 a 4 ". Tal resultado além de refletir a realidade da comunidade no momento específico da realização da pesquisa, também reflete o entendimento e as percepções dos entrevistados sobre a dinâmica da comunidade em tal momento - portanto, é fundamental como ponto de partida para a compreensão da realidade da referida comunidade (embora tal compreensão não deva se limitar a esses aspectos). Como a sociedade humana não é estática, ou seja, a sua dinâmica é contínua, a evolução dos indicadores avaliados poderão sofrer alterações a curto, médio ou em longo prazo, a depender das ações dos agentes internos ou dos agentes externos sobre o ambiente da comunidade, modificando a realidade desta de forma positiva ou de forma negativa.

Das três dimensões levadas em consideração na pesquisa, nenhuma alcançou o limiar de sustentabilidade "3,2", correspondente ao limite mínimo do intervalo correspondente a alta sustentabilidade. As respostas dos moradores aos indicadores direcionaram as três dimensões para a qualidade de média sustentabilidade ambiental, representada pelo intervalo 1,6 a $<2,4$, sendo que a dimensão social obteve a pontuação final 1,683; a dimensão econômica obteve a pontuação final 1,737; e a dimensão uso e gestão dos recursos naturais e tecnológicos obteve a pontuação final 1,961 (Tabela 1). Os temas mais bem avaliados se encontram na dimensão econômica, e são: renda, com resultado 2,829; escoamento e comercialização do produto principal (olericultura) desenvolvido na comunidade, com resultado 2,776; e composição da renda, com resultado 2,691. Por sua vez, dos quatro temas com pior avaliação três são da dimensão econômica e um é da dimensão social, e são: assistência técnica, com resultado 0,195 (dimensão econômica); educação e capacitação, com resultado 0,939 (dimensão social); crédito agrícola, com resultado 1 (dimensão econômica); políticas de seguro para produtos 
agrícolas, com resultado 1 (dimensão econômica). Dos indicadores, os que foram mais bem avaliados são: presença de posto de saúde na comunidade em funcionamento, resultado 3,685 (dimensão social); presença de profisssionais de saúde na comunidade, resultado 3,545 (dimensão social); e quem determina os preços dos produtos, resultado 3,544 (dimensão econômica). Por sua vez, os indicadores com piores resultados na avaliação são: frequência de famílias que receberam cursos para alguma atividade nos últimos três anos, resultado 0 (dimensão social); existe seguro contra perda de produtos por motivo de enchente, estiagem ou fogo, resultado 0 (dimensão econômica); e gestão dos resíduos para efluentes de criatório de animais, resultado 0,024 (dimensão do uso e gestão dos recursos naturais e tecnológicos).

Tabela 1. Índice Geral de Sustentabilidade Ambiental da CRFP de Ipiaú (Bahia), 2015.

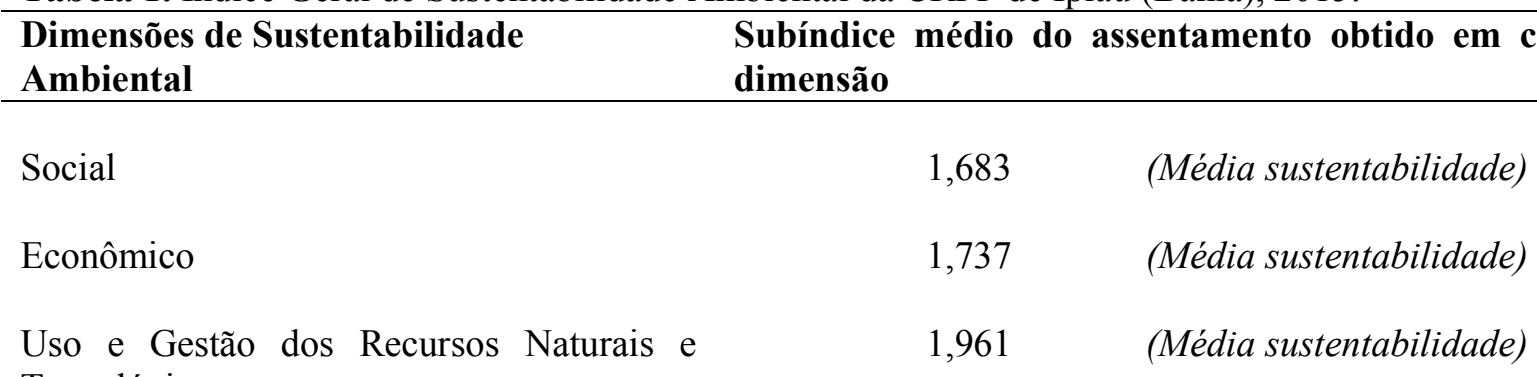
Tecnológicos

Índice geral de sustentabilidade ambiental $\mathrm{Y}_{\mathrm{i}} / \mathrm{n} 5,381 / 3=\mathbf{1 , 7 9 4}$ (Média sustentabilidade) da comunidade

Fonte: Dados da pesquisa (2015).

A seguir são apresentadas breves considerações sobre cada dimensão permitindo melhor compreensão da realidade da comunidade estudada em sua sustentabilidade.

Sustentabilidade na dimensão social

A dimensão social de uma comunidade diz respeito às condições de vida coletiva/ em sociedade (AGUIAR, 2016), sendo consideradas as relações interpessoais e coletivas e a dinâmica dessa coletividade humana. Nessa dimensão, o bem estar social é a expressão maior de sua sustentabilidade e é alcançado a partir da promoção das reais condições para que as aspirações pessoais e coletivas da comunidade sejam realizadas a partir de um estado objetivo e positivo de cada indivíduo. Essa dimensão envolve diferentes aspectos de primordial importância para o seu desenvolvimento, e influencia diretamente a tendência das outras dimensões, as quais também a influenciam, em uma relação dialética. Tais aspectos, 
expressos por meio de indicadores, ao serem avaliados revelam a realidade da comunidade por meio do dimensionamento de suas características.

No estudo desenvolvido sobre a CRFP, para o posicionamento dos entrevistados no que se refere aos indicadores da dimensão social, foram levados em consideração sete temas: 1 . Educação e capacitação; 2. Informação; 3. Saúde e hábitos culturais; 4. Segurança; 5. Mobilidade; 6. Participação e representação; e 7. Percepção do lugar (Figura 2). Cada tema contém um conjunto de indicadores (base para avaliação dos temas que por sua vez permitiram a avaliação da dimensão). Dos sete temas levados em consideração na dimensão social, nenhum alcançou o limiar de sustentabilidade " 3,2 " da escala adotada na pesquisa "0 a 4", ou seja, o limite mínimo do intervalo da alta sustentabilidade $(3,2 \mathrm{a} \leq 4)$. O tema que mais se aproximou do limiar de sustentabilidade foi "Saúde e hábitos culturais", com a pontuação de 2,571 (média-alta sustentabilidade, representada pelo intervalo 2,4 a $<3,2$ ). Por sua vez, o tema que ficou mais distante do limiar de sustentabilidade foi "Educação e capacitação", com a pontuação de 0,939 (baixa-média sustentabilidade ambiental, representada pelo intervalo 0,8 $\mathrm{a}<1,6)$. Dentre os indicadores contidos nos diferentes temas da dimensão social, aqueles que se apresentaram em situação mais crítica na escala de sustentabilidade, configurando sustentabilidade não alcançada, foram: frequência de famílias que receberam cursos para alguma atividade nos últimos três anos (pontuação 0 - baixa sustentabilidade); e disponibilidade de veículos na comunidade para transporte dos moradores para atendimento emergencial na cidade (pontuação 0,207 - baixa sustentabilidade). Os indicadores que apresentaram melhores resultados na escala de sustentabilidade foram: presença de posto de saúde na comunidade em funcionamento (pontuação 3,685 - alta sustentabilidade); e presença de profissionais de saúde na comunidade (pontuação 3,545 - alta sustentabilidade).

A dimensão social da CRFP apresenta alguns aspectos positivos, como, por exemplo, o forte sentimento de comunidade e o apego ao lugar por parte dos moradores, o envolvimento de mulheres e crianças em atividades coletivas, integridade cultural/religiosa, e o forte sentimento de vizinhança - o que desencadeia um conjunto de relações sociais de proximidade entre eles. Além disso, a comunidade é beneficiada com um conjunto de serviços públicos no local (educação para as séries iniciais; profissionais de saúde e posto médico; e mobilidade transporte comercial, transporte público e para estudos na cidade), e benefícios sociais. Há também uma significativa taxa de crescimento da população, sobretudo de crianças e jovens, 
o que aponta significativa expectativa de renovação da população e melhora das condições futuras da comunidade.

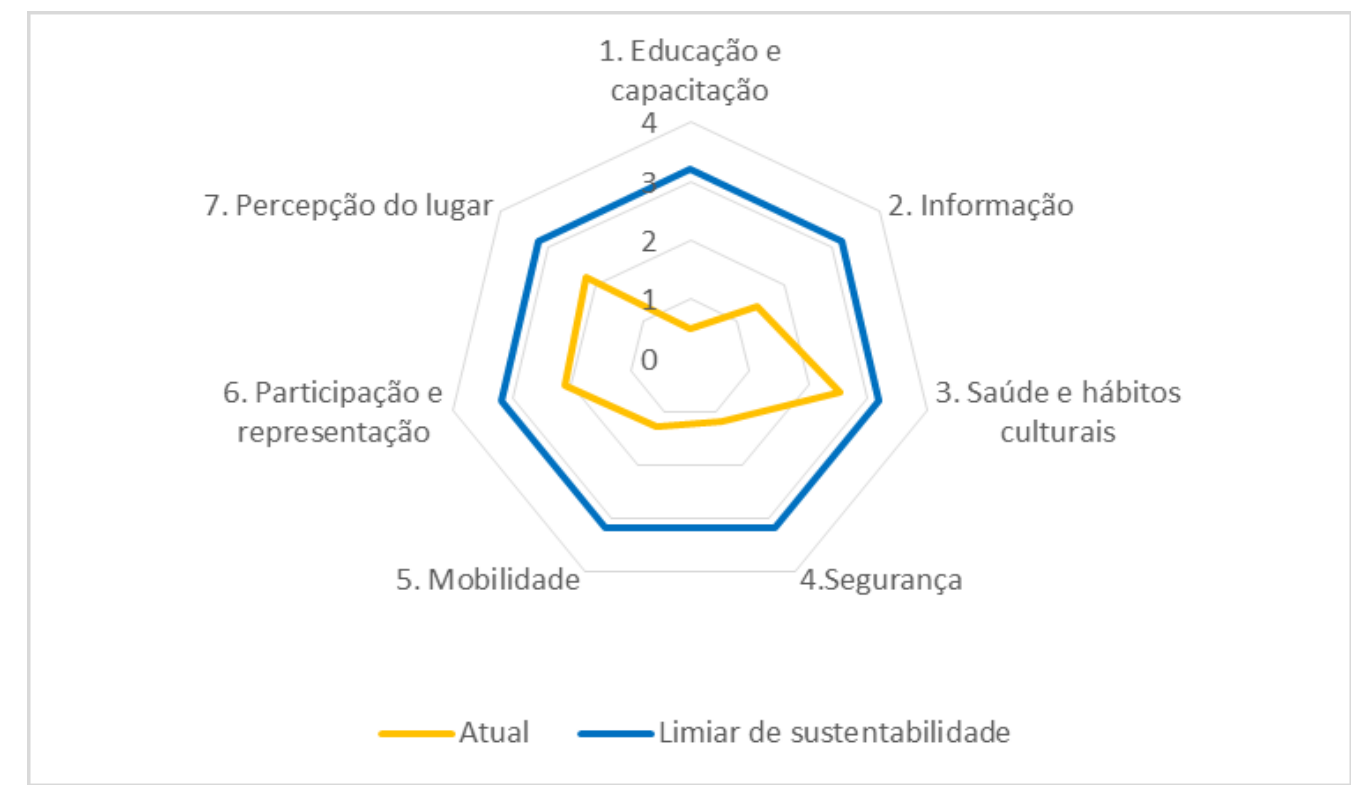

Figura 2. Avaliação dos temas da dimensão social da CRFP, Ipiaú, Bahia (2015). Fonte: Dados da pesquisa (2015).

No que se refere às relações interpessoais e comunitárias, há o predomínio de relações amistosas e de afetividade, em contraste às relações de conflito perduráveis que poderia comprometer a estabilidade social da comunidade no tempo. Embora não haja na comunidade a presença fixa de nenhuma instituição de repressão à violência (a exemplo da polícia), os próprios moradores, na maioria dos casos, dão conta de resolver situações de conflito - em raras vezes que ocorre. No entanto, segundo alguns moradores, tem aumentado o número de furtos em residências do lugar (embora com baixa incidência) - o que atribuem em especial ao fato de estar aumentando o número de pessoas de fora da comunidade que estão se fixando ou mesmo frequentando o espaço desta.

Por outro lado, a comunidade apresenta algumas situações que poderiam ser entendidas como fragilidades: dependência em relação ao representante da comunidade na busca de certas melhorias junto ao poder público; ausência de educação de jovens e adultos voltada para o campo; defasagem série-idade; baixa garantia de segurança pública; ausência de cursos de capacitação profissional; baixa representatividade da liderança; ausência de unidade escolar de ensino fundamental II, ensino médio e profissionalizante; baixo engajamento masculino em atividades coletivas; baixa participação familiar na associação; ausência de engajamento político de jovens e de participação em associações desse tipo; inadequação de 
espaço para reuniões coletivas; e ausência de planejamento de longo prazo da comunidade. Além disso, algumas situações ocorrentes podem ser entendidas como ameaças à comunidade, como a influência política por parte de agentes do Poder Público Municipal neutralizadora de ações e decisões da comunidade; e ausência de políticas e programas de desenvolvimento em longo prazo da comunidade por parte do Poder Municipal.

Sustentabilidade na dimensão econômica

A dimensão econômica de uma comunidade diz respeito à capacidade de reprodução da vida e de acesso aos bens e serviços necessários (capacidade material - a exemplo de ocupação do trabalho, acesso à renda, etc., o que desencadeia a possibilidade da comunidade atender as suas necessidades fundamentais, como moradia, alimentação, vestuário, transporte, educação..., e vislumbrar a realização de necessidades secundárias). Essa dimensão é de fundamental importância para reprodução e permanência da comunidade no tempo.

Para a avaliação da sustentabilidade ambiental da CRFP na dimensão econômica foram levados em consideração sete temas: 8. Área produtiva; 9. Composição da renda; 10. Renda; 11. Crédito agrícola; 12. Assistência técnica; 13. Escoamento e comercialização do produto principal (oleiricultura) desenvolvido na comunidade; e 14. Políticas de seguro para produtos agrícolas (Figura 3). Dentro de cada tema estão contidos os indicadores, base para avaliação dos temas, que por sua vez permitiram a avaliação da dimensão. Dos sete temas avaliados na dimensão econômica, nenhum alcançou o limiar de sustentabilidade "3,2". O tema que mais se aproximou do limiar de sustentabilidade foi "Renda", com resultado 2,829 (média-alta sustentabilidade ambiental, representada pelo intervalo 2,4 a $<3,2$ ). Por sua vez, o tema que ficou mais distante do limiar de sustentabilidade foi "Assistência Técnica", com resultado 0,195 (baixa sustentabilidade ambiental - intervalo $0 \mathrm{a}<0,8$ ). Dentre os indicadores contidos dentro dos diferentes temas na dimensão econômica, aqueles que se apresentaram em situação mais crítica na escala de sustentabilidade, foram: existe seguro contra perda de produtos por motivo de enchente, estiagem ou fogo (resultado 0 - baixa sustentabilidade); satisfação em relação a assistência técnica recebida (resultado 0,195 - baixa sustentabilidade); existe crédito agrícola para seu lote (resultado 1 - baixa-média sustentabilidade); e a associação da comunidade tem acesso ao crédito agrícola (resultado 1 - baixa-média sustentabilidade). Os indicadores que apresentaram melhores resultados na escala de sustentabilidade foram: quem determina os preços dos produtos (resultado 3,544 - alta sustentabilidade); renda obtida de 
atividades não agrícolas (resultado 3,516 - alta sustentabilidade); e como é feito o transporte do produto para o local de venda (resultado 3,509 - alta sustentabilidade).

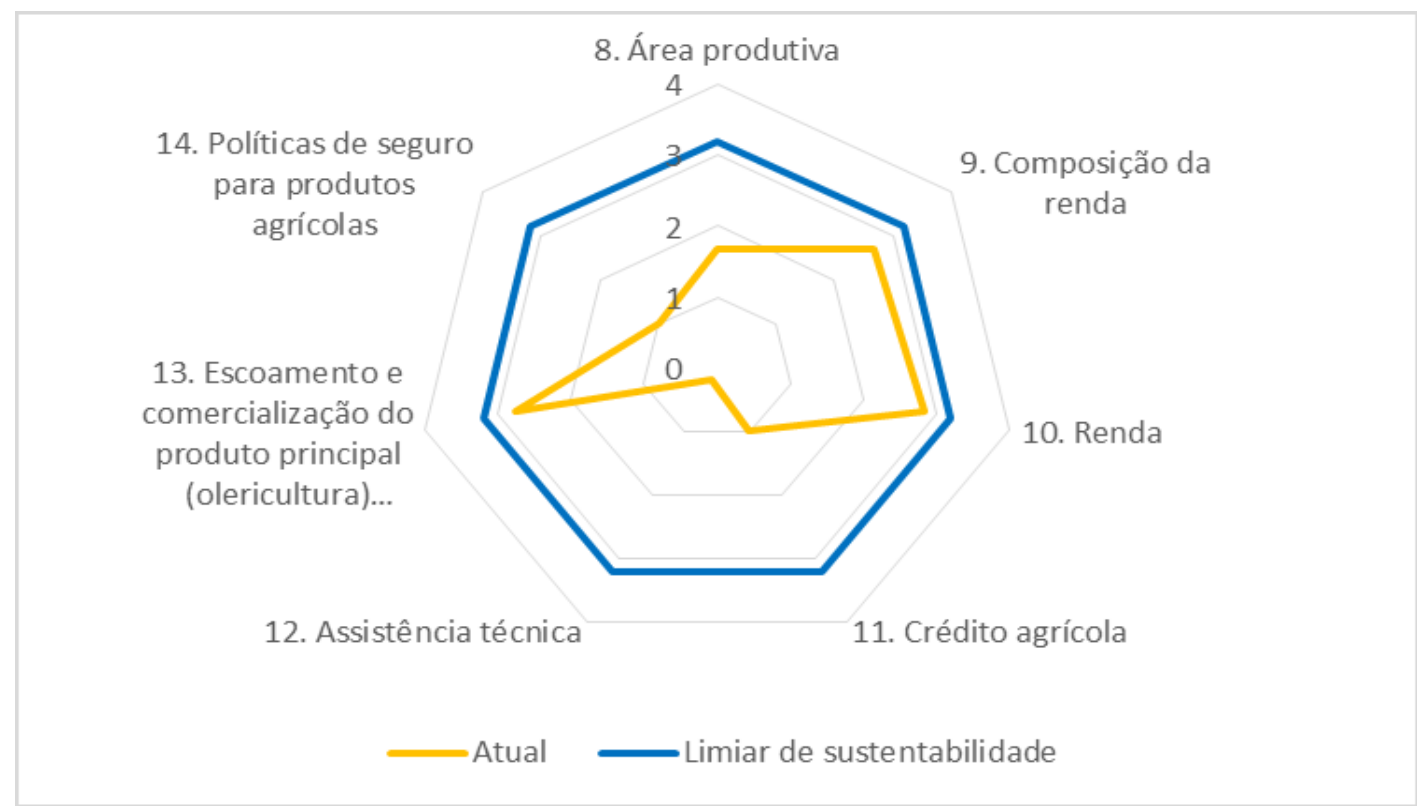

Figura 3 - Avaliação dos temas da dimensão econômica da CRFP, Ipiaú, Bahia, 2015. Fonte: Dados da pesquisa (2015).

Para sua subsistência, a maior parcela das famílias residentes na comunidade tem como base a produção predominante de hortaliças folhosas, a qual é responsável de forma significativa pela geração de renda para as famílias que desenvolve esse tipo de produto em suas Unidades de Produção Familiar (UP). A base da renda das famílias é provinda de atividades agrícolas (dentro ou fora da comunidade), atividades não agrícolas (dentro ou fora da comunidade) e benefícios sociais. A maior parcela dos moradores da comunidade trabalha em atividades agrícolas dentro da própria comunidade. Foram identificadas 77 Unidades Produtivas Familiares na CRFP, utilizadas em sua maioria na produção de hortaliças folhosas. As maiores concentrações dessas unidades de produção se dão em áreas de brejo, na agrovila.

Fatores como o significativo potencial produtivo em pequenas unidades de produção familiar em curto prazo, disponibilidade de transporte público gratuito para escoamento da produção, conhecimento tradicional no processo produtivo, e absorção da mão-de-obra familiar, são aspectos que podem ser apontados como positivos na comunidade.

Por outro lado, a ausência de cooperativas, falta de interesse e mobilização para acesso aos programas de absorção dos produtos agrícolas (PAA e PNAE) por parte dos moradores, distribuição desproporcional de terras entre as famílias, exaustão do potencial produtivo em 
longo prazo, crescimento populacional/famílias desproporcional a disponibilidade de terras, e comercialização ilegal de terras a pessoas de fora e de dentro da comunidade, são aspectos que podem trazer certas fragilidades a comunidade. Outro aspecto negativo que pôde ser identificado na comunidade é o fato de moradores (poucos) se servirem do lixão público, que se situa em uma fazenda ao lado da comunidade, para catarem objetos que lhes possibilitem obterem recursos financeiros - essa identificação só pôde ser feita a partir de visita ao lixão, pois nenhum morador apontou esse fato nas entrevistas (algo que causou surpresa, pois as respostas dadas pelos moradores ao formulário de entrevista não apontou nenhuma situação familiar precária que justificasse a busca por meios de sobrevivência através do lixão).

A falta de acesso a políticas de seguro para produção agrícola, falta de fiscalização do poder público municipal com relação a ocupação de terras dentro da comunidade, ausência de assistência técnica, e desatualização documental dos lotes são fatores ameaçadores ao bem estar econômico da comunidade. Há desatualização por parte do Poder Público Municipal na regularização dos contratos de comodato das famílias, que deveria ocorrer a cada dois anos, o que favorece a prática comum na comunidade de venda não legalizada de terrenos entre os próprios moradores, ou a entrada de novos moradores os quais compram terrenos junto a antigos moradores. As famílias pesquisadas da comunidade demonstraram alto nível de insatisfação em relação à assistência técnica recebida/ ou não recebida/ da EBDA e da EMBRAPA. Um percentual de 65,8\% das 111 famílias da comunidade se mostraram insatisfeitas com a EBDA (Empresa Baiana de Desenvolvimento Agrícola. Empresa essa que no correr do ano de 2015 foi extinta - posterior à realização da pesquisa); e 66,7\% das famílias se mostraram insatisfeitas com a EMBRAPA.

Sustentabilidade na dimensão do uso e gestão dos recursos naturais e tecnológicos

A Dimensão do Uso e Gestão dos Recursos Naturais e Tecnológicos diz respeito ao estado de conservação dos recursos que a comunidade utiliza para gerar renda e/ou bens e serviços necessários e a gestão dos resíduos produzidos na comunidade.

Para a avaliação da sustentabilidade ambiental da CRFP na dimensão do uso e gestão dos recursos naturais e tecnológicos foram levados em consideração quatro temas: 15 . Conservação do solo, dos recursos hídricos e florestais; 16. Proteção dos plantios; 17. Gestão dos agroquímicos; 18. Saneamento básico /Gestão dos resíduos (Figura 4). Dentre os quatro temas selecionados, nenhum alcançou o limiar de sustentabilidade " 3,2 " dentro da escala 
adotada de 0 a 4 . O tema que mais se aproximou do limiar de sustentabilidade foi "Gestão dos Agroquímicos", com resultado obtido de 2,442 (média-alta sustentabilidade, representada pelo intervalo $2,4 \mathrm{a}<3,2$ ). Por sua vez, o tema mais distante do limiar de sustentabilidade foi "Proteção dos plantios", com resultado obtido de 1,434 (baixa-média sustentabilidade, representada pelo intervalo $0,8 \mathrm{a}<1,6)$.

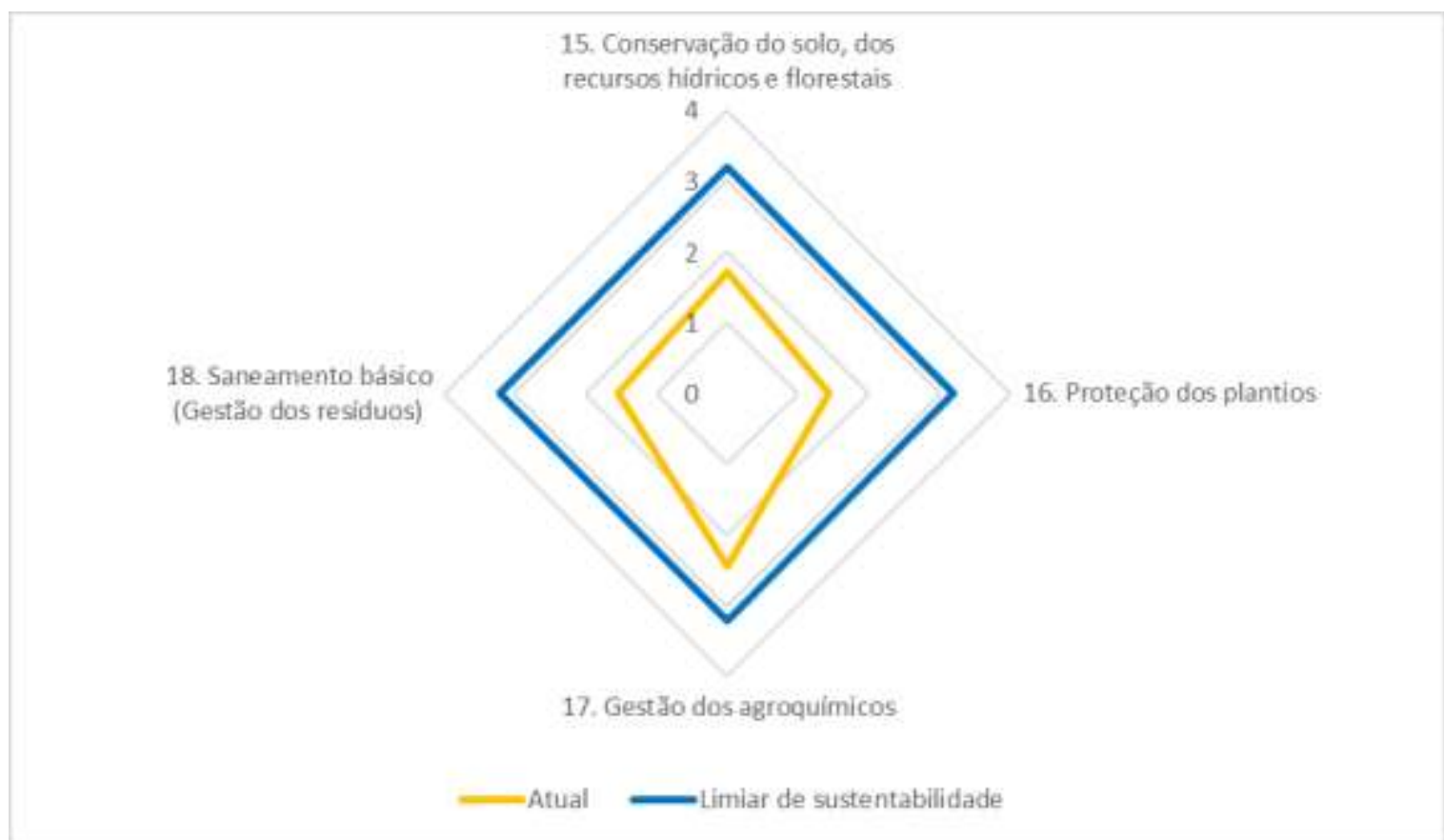

Figura 4 - Avaliação dos temas da dimensão Uso e Gestão dos Recursos Naturais e Tecnológicos da CRFP de Ipiaú (Bahia), 2015

Fonte: Dados da pesquisa (2015).

Nessa dimensão, os indicadores que se encontram em situação mais crítica dentro da escala de sustentabilidade são: b. gestão dos resíduos para efluentes de criatório de animais (baixa sustentabilidade - resultado 0,024); e c. frequência em que os moradores utilizam os recursos florestais da comunidade (baixa sustentabilidade - resultado 0,937). Os indicadores que se encontram em melhor situação dentro da escala de sustentabilidade são: local de destino dos resíduos orgânicos (alta sustentabilidade - resultado 3,315); e destino dos resíduos, e embalagens dos defensivos agrícolas, depois de vazios (média-alta sustentabilidade - resultado 2,442).

Há na comunidade uma significativa frequência de famílias que se utilizam dos recursos florestais presentes no seu território, tanto no que se refere a estacas quanto a mourões, ou mesmo para outros tipos de utilizações, o que colocou o indicador agregado em situação de baixa sustentabilidade (resultado 0,937). Essa situação não é favorável à comunidade, 
sobretudo porque no transcurso da existência da comunidade muitas áreas de florestas foram suprimidas, e atualmente há significativas áreas de pasto, em sua maioria ao redor de áreas de cacau cabruca.

Para o indicador métodos utilizados para prevenção e controle de pragas, insetos e doenças obteve-se um resultado positivo para a comunidade porque as maiores pontuações obtidas estiveram para métodos biológicos, tratos e captura manual, e nenhum método (se contabilizados juntos) - pois são métodos considerados sustentáveis, e elevaram o resultado do indicador; embora a maior frequência de pessoas por método individualmente tenha sinalizado que utiliza agrotóxico (39 pessoas), equivalente a pontuação 0. De igual forma, o indicador destino dos resíduos e embalagens dos defensivos agrícolas depois de vazios obteve resultado positivo no aspecto da sustentabilidade, pois das 111 famílias da comunidade 50 sinalizaram não utilizar defensivos agrícolas, 24 famílias destinam para o serviço de coleta pública e 27 famílias não possuem unidades de produção ou não estavam desenvolvendo cultivos no período da pesquisa, o que perfazem juntos 101 famílias, ou seja, $91 \%$ das 111 famílias.

Os aspectos mais frágeis para essa dimensão identificados na comunidade são: Falta d'água para a maioria das unidades de produção familiar (UP), qualidade ruim e má distribuição hídrica para as UP, remoção da vegetação, ausência de tecnologias sociais de saneamento básico nas unidades produtivas, e perda de nutrientes do solo.

\section{Considerações Finais}

O atual modelo de desenvolvimento adotado pela sociedade industrial capitalista com seu estilo de vida consumista, ou mesmo o tão propagado desenvolvimento sustentável com a formulação do seu conceito pelas elites em esfera governamental, não tem sido capaz de responder as inquietações e contradições advindas da relação sociedade-natureza, no sentido de garantir o desenvolvimento da sociedade humana e suas instituições, em diferentes regiões e em suas peculiaridades culturais e institucionais, possibilitando ao mesmo tempo a conservação da natureza com qualidade, tanto para o presente, quanto para o futuro.

Como alternativa a essa realidade, os estudos de avaliação da sustentabilidade ambiental de comunidades humanas vêm ganhando destaque nas últimas décadas. Esses estudos, em grande medida, visam diagnosticar o estágio de sustentabilidade ambiental em que se encontram essas comunidades, por meio da avaliação de cada dimensão a partir de um sistema 
de indicadores, permitindo assim apontar os aspectos mais frágeis nessas comunidades, o seu monitoramento, e a adoção de políticas de melhorias.

O estudo de avaliação da sustentabilidade ambiental desenvolvido na CRFP foi uma experiência nesse sentido, e apontou que a referida comunidade, diferente de alguns outros tipos de assentamentos de reforma agrária da região, apresenta-se em uma situação relativamente satisfatória em alguns aspectos, conforme evidenciado por indicadores.

A hipótese que norteou esta pesquisa de que a comunidade se encontra em um nível global de baixa sustentabilidade ambiental das dimensões consideradas, acompanhando a tendência de demais assentamentos brasileiros, foi refutada, pois os resultados da pesquisa apontam que a comunidade, de forma geral, encontra-se no nível de média sustentabilidade ambiental, e individualmente cada dimensão considerada na pesquisa também se encontra no nível de média sustentabilidade ambiental.

A CRFP além de importante para o município de Ipiaú (embora sua população represente apenas $0,9 \%$ da população municipal total), também apresenta dados positivos no que se refere à composição da sua população (com a pirâmide etária larga na base), à taxa de permanência no lugar por parte da população jovem e adulta, à saúde, à renda e à renda per capita, ao sentimento de apego ao lugar, etc. Ficou, no entanto, evidente na comunidade a necessidade que os moradores têm de acompanhamento específico por parte das instituições de capacitação e apoio técnico, tanto no que se refere a qualifica-los para o trabalho agrícola, quanto para dar-lhes assistência na produção (priorizando a utilização de manejos considerados limpos), no acesso ao crédito e seguros, e como lidarem com esse crédito e quitá-lo, dentre outros aspectos.

Como vimos, um dos aspectos mais vulneráveis da dimensão social da sustentabilidade da Fazenda do Povo consiste justamente na sua pouca organização coletiva formal, o que dificulta o acesso a políticas públicas e linhas de financiamento agrícola, bem como o acesso a redes de consumidores específicos como os do mercado de produtos orgânicos. No contexto local pudemos perceber certo descrédito em relação à representação política e suas organizações como a associação de moradores que tem atualmente uma baixa adesão. Muitas razões contribuem para este estado de coisas, como o desgaste de lideranças prévias e o favoritismo a determinados colaboradores em detrimento de outros. A falta de transparência nos afazeres da associação e mesmo seu envolvimento com disputas eleitorais também podem possíveis razões do interesse das pessoas em participar ativamente do cotidiano das 
associações. De uma maneira mais ampla podemos falar de um desinteresse nacional pelo que é político, em todas as escalas, a menos que algum interesse particular esteja em questão. Jacobi, Toledo e Grandisioli (2016) destacam o fundamental papel do aprendizado social e da educação para a sustentabilidade deixar de ser apenas um conceito e passar a ser encarnada pelos atores sociais. Neste sentido, a educação pública tem uma função incomensurável, seu papel de formadora para a cidadania e sustentabilidade não poderia ser mais explícito. $\mathrm{Na}$ contra mão vemos a educação brasileira, apesar de avanços significativos da última década, esvaziada de seu papel, sabotada por meio de baixos investimentos e desvalorização de seus profissionais. Índices recentes, sobretudo em relação ao ensino médio, evidenciam a necessidade de novas estratégias e de mais investimento na educação pública que, nos tempos atuais, está longe de ser uma prioridade para os governantes. O próprio modelo de educação, apoiado no sucesso individual, esvazia o potencial coletivo para a transformação e mudança do contexto imediato.

Do estudo que realizamos, acreditamos que a metodologia adotada se constitui um modelo de avaliação da sustentabilidade ambiental que pode ser replicada e adaptada ao contexto de qualquer comunidade localizada, isso em razão dos resultados satisfatórios que obtivemos - o que nos permite propô-la como alternativa aos estudos de desenvolvimento sustentável (para o caso de grupos humanos localizados) que normalmente são generalistas, de cima para baixo e que apresentam ambiguidades. A nossa proposta de avaliação da sustentabilidade ambiental de comunidades localizadas conquanto apresente lacunas, por estar em aperfeiçoamento, e não dê conta de enfrentar o modelo econômico vigente em sua totalidade, é uma proposta eficaz e propicia subsídios para a adoção de políticas de desenvolvimento dessas comunidades por parte das esferas que as administram (municipal, estadual ou federal), ou mesmo para apoiar movimentos internos de autogestão dentro dessas comunidades no sentido da melhoria de suas condições e sua permanência com qualidade no tempo - ou seja, para o estabelecimento de um conjunto de relações sociais em resistência ou contestação à lógica econômica global manifestada nos lugares. Esperamos, portanto, ter auxiliado para o desenvolvimento de ferramenta de avaliação que contribua com outras pesquisas científicas voltadas para a temática em questão em outros contextos.

Nota: Neste artigo são apresentados apenas alguns dos resultados obtidos com a pesquisa. Os outros resultados compõem outros artigos. 


\section{Referências}

AGUIAR, P. C. B. de. Entre a noção de desenvolvimento sustentável e a possibilidade da construção de comunidades e sociedades sustentáveis. Revista Científica Monfragüe:

Desarrollo Resiliente, Universidad de Extremadura, Espanha, vol. VI, nº 2, p. 104-117, abril, 2016.

AGUIAR, P. C. B. de.; BRUNO, N. L.; SAMPAIO, L. A. G.; COSTA, L. C. B. Desafios ao desenvolvimento do assentamento rural Coroa Verde, Município de Barra do Rocha, Estado da Bahia, Brasil. Revista Entorno Geográfico, Universidad del Valle, Cali, Colômbia, $\mathrm{n}^{\mathrm{o}}$ 11, p. 86-113, Enero/Diciembre, 2015.

ALENCAR-LINARD, Z. Ú. S. de.; SAEED-KHAN, A.; LIMA, P. V. P.-S. Percepções dos impactos ambientais da indústria de cerâmica no município de Crato estado do Ceará, Brasil.

Economía, Sociedad y Territorio, México, vol. xv, núm. 48, 2015, p. 397-423.

BELLEN, H. M. V. Indicadores de sustentabilidade: uma análise comparativa. Rio de Janeiro: Ed. FGV, 2006.

BRANDEMBURG, A. Do rural tradicional ao rural socioambiental. Ambiente \&Sociedade, Campinas, v. XIII, n. 2, p. 417-428, jul.-dez. 2010.

BRÜSEKE, F. J. O problema do desenvolvimento sustentável. In : CAVALCANTI, C. (Org.). Desenvolvimento e natureza : estudos para uma sociedade sustentável. 3. Ed. São Paulo : Cortez ; Recife, PE : Fundação Joaquim Nabuco, 2001. p. 430

CAMARANO, A. A.; ABRAMOVAY, R. Êxodo rural, envelhecimento e masculinização no Brasil: panorama dos últimos cinqüenta anos. Revista Brasileira de Estudos de População, v. 15, n. 2, p. 45-65, jul./dez. 1998.

CAPORAL, F. R.; COSTABEBER, J. A. Análise Multidimensional da Sustentabilidade : Uma proposta Metodológica a partir da Agroecologia. Agroecol. E Desenv. Rur. Sustent., Porto Alegre, v.3, n. 3. Jul/Set, 2002.

CARVALHO, P. G. M.; BARCELLOS, F. C. Políticas públicas e sustentabilidade ambiental: construindo indicadores de sustentabilidade. 2009.

CASTILHO, M. A. de.; ARENHARDT, M. M; LE BOURLEGAT, C. A. Cultura e identidade: os desafios para o desenvolvimento local no assentamento Aroeira, Chapadão do Sul, MS. INTERAÇÕES, Campo Grande, v. 10, n. 2, p. 159-169, jul./dez. 2009. Disponível em: <http://www.scielo.br/pdf/inter/v10n2/v10n2a04.pdf> Acesso em: 30 set. 2013.

CAVAlCANTI, C. Uma Tentativa de Caracterização da Economia Ecológica. Ambiente \& Sociedade - Vol. VII n ${ }^{\circ}$. 1, p. 149-158, jan/jun. 2004.

COLlins, P. H. The New Politics of Community. American Sociological Association. University of Maryland, 2010.

DIEGUES, A. C. Sociedades e comunidades sustentáveis. São Paulo: Nupaup-USP, 2003.

Disponível em: $<$ http://nupaub.fflch.usp.br/sites/nupaub.fflch.usp.br/files/color/comsust.pdf $>$ Acesso em: 30 set. 2013.

INCRA. Instituto Nacional de Colonização e Reforma Agrária. Relação dos Projetos de Reforma Agrária do Brasil. Brasília, DF: Diretoria de Obtenção de Terras e Implantação de Projetos de Assentamento (DT), 2011.

JACOBI, P. R.; TOLEDO, R. F. de; GRANDISOLI, E. Education, sustainability and social learning. Brazilian Journal of Science and Technology, (2016) 3:3. Disponível em: https://bjst-journal.springeropen.com/articles/10.1186/s40552-016-0019-2. Acesso em: 15 set. 2016.

LEFF, H. SABER AMBIENTAL: SUSTENTABILIDADE, RACIONALIDADE, COMPLEXIDADE, PODER. Petrópolis: Vozes, 2001. 
MAUERHOFER, V. 3-D Sustainability: an approach for priority setting in situation of conflicting interests towards a Sustainable Development. Ecological Economics, Vol. 64, n. 3, pp. 496-506, 2008.

MARQUES, M. I. M. O conceito de espaço rural em questão. Terra Livre, São Paulo, Ano 18, n. 19, p. 95-112, jul./dez. 2002.

NGUIRAZE, A. C.; AIRES, J. D. M. Moçambique: processos de participação das comunidades rurais no desenvolvimento local. Revista IDeAS, v. 5, n. 1, p. 30-65, 2011. PEREIRA, T. M.S.; SILVA, J. B.; SILVA FILHO, A. P. C. As dinâmicas rurais no contexto do desenvolvimento: Estudo de caso do assentamento Cícero Romana I - Paraíba. Revista Geográfica Acadêmica, Boa Vista, Roraima, v. 8, n. 2, p. 47-58, nov./dez., 2014.

Recebido em fevereiro de 2016. Aceito em dezembro de 2016. 